\title{
Assessing L2 listening in CALL and listening strategy use
}

\section{Cristina Pardo-Ballester}

Department of World Languages and Cultures, Iowa State University, Iowa, U.S.A.

\begin{abstract}
This longitudinal study examines students' learning strategies of 222 Spanish intermediate learners when taking several listening tests. It also examines the effect of different instructional formats (online-hybrid vs. face2face-blended) on the learners' strategy use. There were four versions of the same aural text: an audio format, a video format, a redundancy-enhanced version in audio format, and a redundancy-enhanced version in video format. A pseudocrossover design was utilized for this study with four listening tests used with each online-hybrid, face2face-blended and control groups. Participants completed a questionnaire immediately after each listening test to learn about learners' strategies before, during and after listening in order to elicit information about the particular strategies that learners used to complete each listening test.

Results indicated that there was a listening comprehension strategy development over time without explicit instruction, but participants from different instructional formats developed different strategies. There was a statistically significant difference for intermediate-low learners when perceiving the use of cognitive and metacognitive strategies, but the effect of redundancy does not seem to help students to use different types of strategies. Intermediate-mid learners did not perceive a difference with the use of strategies when completing listening tests with or without redundancy.
\end{abstract}

Keywords:listening strategies; online-hybrid; face2face-blended;redundancy. 


\section{Introduction}

When teaching a foreign language such as Spanish within the first three years of undergraduate studies, there is not always time in the classroom to teach listening strategies, especially if the textbook in use does not include a section to improve listening comprehension (LC). However, there are many studies about the importance of teaching listening strategies to help achieve comprehension (Nogueroles López \& Blanco Canales, 2017; Roussel, 2011; Vandergrift, 2008), but the reality is that even when a textbook includes a section with listening strategies, not much time is devoted to help learners develop cognitive and metacognitive strategies. Instead, students read on their own the listening strategy section and practice their listening with online resources from the adopted textbook or external applications.

After fifteen years of teaching, observing, and evaluating foreign language classes in my role as a graduate student, researcher, assistant, and associate professor in three American research universities, I noticed that listening strategies are not taught unless a research project is conducted or the adopted textbook includes a section on how to develop listening strategies. Instead, foreign language instructors use the target language with extensive comprehensive input for their students to fend for themselves in communication situations. Instructors also do their best to include communicative activities in their lesson plans with the idea that their students will speak the target language. Furthermore, today more instructors include applications of online computer assisted language learning (CALL) in their programs as part of homework to facilitate language learning. When doing listening activities in the classroom, some instructors ask their students to read the context, instructions, and questions before listening to the audio repeated times. Then, the instructor will allow students time to answer LC questions.

There are many research studies in L2 listening strategies in the classroom setting, but there is a scarcity of studies with online CALL settings (Chen et al., 2013). Previous research has focused on teaching, proficiency levels and reporting listening strategies in a classroom setting (Nogueroles López \& Blanco Canales, 2017; Vandergrift, 2008). Roussel (2011) tracked the movements of the computer mouse while a learner listened to an aural text in order to represent L2 learners' listening strategies, reporting not only what learners say that they did, but what they really did. Chen et al., (2014) used a web-based CALL setting to explore how motivation, learning styles and anxiety affect the learners' strategy use. Both studies were done within a learning environment, but the present study was conducted within a testing environment. Suvorok (2018) investigated test-taking strategies using eye tracking and cued retrospective reporting when L2 English learners responded listening, reading and grammar items within a computer-based English test. There is need to examine L2 listening strategies within testing and online CALL settings. 
This study, therefore, addressed the following research questions in order to specify the listening strategies that learners of Spanish report before, during, and after listening to different aural messages within different instructional formats and different versions of the same aural text within testing and online CALL settings: (1) Are students in the onlinehybrid courses using more cognitive strategies than students from face2face-blended classrooms? (2) Does student listening comprehension strategy use develop over time without explicit instruction? (3) Does providing redundant information in listening texts facilitate student use of certain strategies?

\section{Listening strategies in CALL}

LC is one of the skills needed for language acquisition, but it is also the least understood (Vandergrift \& Baker, 2015).Vandergrift's (2008) chapter presents an overview of the strategies used by second/foreign language (L2) listeners to improve their understanding of aural texts, emphasizing the metacognitive and cognitive strategies that direct and control learners' listening efforts. Cognitive strategy relates directly to a learning task and involves the listener's direct manipulation or transformation of learning materials (Goh, 1998). Examples of cognitive strategies, based on Vandergrift (1997) and O'Malley and Chamot (1990), are inferencing (such as linguistic, paralinguistic and kinesic inferencing), elaborating (i.e., using prior knowledge), imaginery (i.e., using mental pictures or visuals), summarizing, translating, repeating a chunk of language, transferring (i.e., using knowledge of one language such as cognates), and taking notes. Metacognitive strategies do not imply a direct processing of input, but rather the executive processing functions of planning, monitoring, and evaluating (Goh, 1998). Metacognitive strategies are important because they oversee, regulate, or direct the language learning process (Vandergrift, 2008). Examples of metacognive strategies, based on O'Malley and Chamot (1990), are planning what needs to be done (i.e, proposing strategies for managing the listening task, directed attention, and selective attention), comprehension monitoring (i.e., checking, self-verifying comprehension at the local level), double-check monitoring (i.e., self-verifying during the second time of listening), and self-evaluating the listening process (i.e., performance selfjudging, strategy evaluation, and problem solving).

Findings of studies comparing low- and high-level listeners reported that effective listeners use twice as many metacognitive strategies as less effective listeners, but to regulate listening and achieve comprehension, metacognitive and cognitive strategies need to be used (Vandergrift, 2008). Vandergrift and Baker (2015) also demonstrated that metacognition is the key for L2 listening success. Regarding the use of CALL, there are research studies demonstrating the advantages of learning and assessing with CALL, such as flexibility, self-paced access of information, and visual support (Chen, et al., 2014; Roussel, 2011). 


\section{The Study}

222 Spanish learners at a Midwestern university participated in this research. They were enrolled in intermediate Spanish courses taught with online-hybrid and face2face-blended formats. 117 were intermediate-low Spanish learners (i.e., Span 201) and 105 were intermediate-mid Spanish learners (i.e., Span 202).

When this study was conducted, the textbook in use for intermediate Spanish learners did not include a listening strategy section. It included listening activities and instructors played the audio using a CD-ROM. Sometimes instructors read the script from the textbook instead of using the CD-ROM. Practice with the listening skill was done in the classroom by listening to the instructor and classmates and by doing listening activities from the text. During tests, instructors controlled the audio, playing it twice. For this study, CALL listening tests were developed with video and audio formats related to the type of listening assessment that students used in the classroom (i.e., monologues as a one-way listening). There were four versions of the same aural text: an audio format, a video format, a redundancy-enhanced version in audio format, and a redundancy-enhanced version in video format (Pardo-Ballester, 2016). The differences from a regular listening test were: test delivery (web-based instead of paper and pencil), texts were enhanced with redundancy and the use of videos instead of just audio. These conditions are favorable for the learners because they have control to play the audio whenever they are ready. It is important to notice that because they were listening assessments and not listening activities for learning, participants could not stop, go back or forward the audio, but they could listen to the audio twice before submitting their five answers for each test. See Figure 1 for test 2.

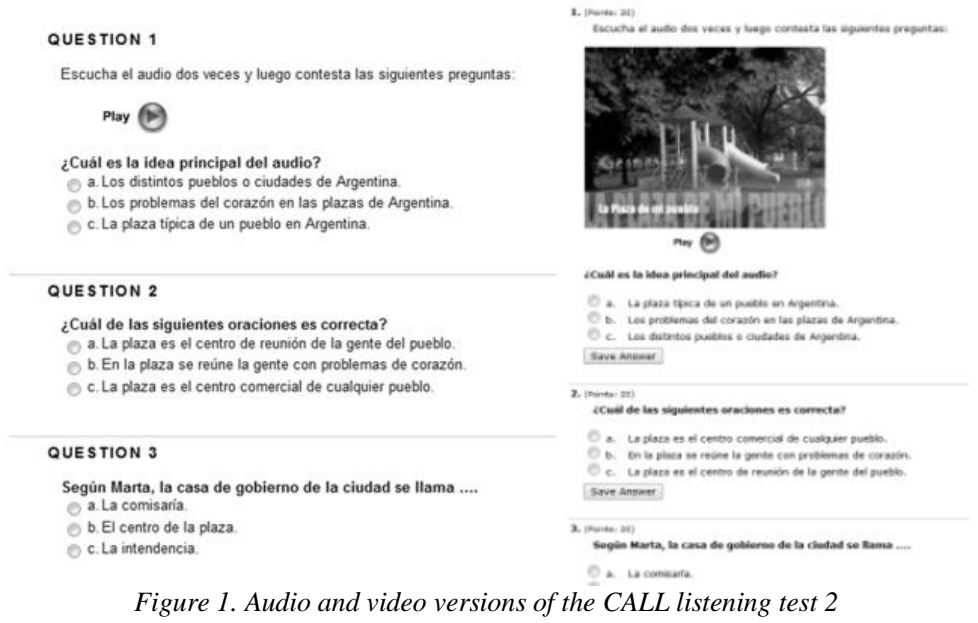

Participants enrolled in face2face-blended courses were present in the classroom three days and one day in the computer lab with the instructor and classmates. The total instructional 
time was 200 minutes (50 mns x 4 days). The online-hybrid participants were present in the classroom two days and one day for an online meeting. The total instructional time was 125 minutes ( $50 \mathrm{mns}$ x $2=100 \mathrm{mins}+25$ mins online meeting $=125 \mathrm{mns}$ ). Both courses had the same learning goals and were taught with the same communicative pedagogy.

\subsection{Data collection}

For this study, participants took four extra listening tests during each semester. They completed these tests one day before their actual test. Each test included five multiplechoice items. It served as a review practice, but with the CALL setting. Immediately after each CALL listening test, learners took an online 10 item questionnaire in order to elicit information about: 1) the listening tests with five multiple-choice items about liking, difficulty, easiness, clarity and sound quality, 2) particular strategies that participants used before, during, and after listening with four open-ended questions, and 3) learning new vocabulary with one open-ended question. Data was collected during two consecutive semesters using a pseudo cross-over design. There were three groups (online-hybrid, face2face-blended and control). Learners from the control group were instructed with a face 2 face-blended format, but they did not take tests enhanced with redundancy.

\subsection{Data Analysis}

To answer the research questions in this study, the data were analyzed using quantitative and qualitative data analysis approaches. The qualitative data from the open-ended survey questions were coded according to the subsections for the metacognitive and cognitive major categories as they have been defined by Vandergrift (1997) and the O'Malley and Chamot (1990) taxonomy of listening comprehension strategies. Two undergraduate students trained in the identification of the categories independently classified the reported strategy use data. Their classifications were compared with those of the researcher and decisions were made. 1 was used to code metacognitive strategies and 2 was used for cognitive strategies. More codes were used to differentiate between the types of metacognitive and cognitive strategies. 1-13 for metacognitive strategies (global prediction, directed attention, selective attention, double check monitoring, performance evaluation, problem identification...) and 14-28 for cognitive strategies (translation, note-taking, summarization, linguistic inferencing...world elaboration). To compare the results for the instructional and ability groups, we looked at the trends in participants' strategy use and types using frequency counts, means, percents and ANOVA.

\section{Findings}

R.Q. 1: Are students in the online-hybrid courses using more cognitive strategies than students from face2face-blended classrooms? 
Table 1. Frequency counts and percent for groups and proficiency levels

\begin{tabular}{ccccccccc}
\hline Groups & \multicolumn{2}{c}{$\begin{array}{c}\text { Cognitive } \\
\text { Frequency }\end{array}$} & \multicolumn{2}{c}{$\begin{array}{c}\text { Percent } \\
\text { Cognitive }\end{array}$} & \multicolumn{2}{c}{$\begin{array}{c}\text { Metacognitive } \\
\text { Frequency }\end{array}$} & $\begin{array}{c}\text { Percent } \\
\text { Meta. }\end{array}$ \\
& IL & IM & IL & IM & IL & IM & IL & IM \\
\hline Online-hybrid & 70 & 27 & $17 \%$ & $11 \%$ & 343 & 219 & $83 \%$ & $89 \%$ \\
F2F-blended & 61 & 45 & $8 \%$ & $15 \%$ & 569 & 252 & $90 \%$ & $85 \%$ \\
Control & 28 & 46 & $7 \%$ & $16 \%$ & 380 & 245 & $93 \%$ & $84 \%$ \\
\hline
\end{tabular}

Intermediate-low (IL) and Intermediate-Mid (IM)

The qualitative data taken from three questions reported what participants did before, during and after listening to the input was tallied. Intermediate-low learners reported answers to these three questions after completing each of four listening tests. Qualitative data for intermediate-mid learners for the same three questions was collected only for three listening tests due to a technology issue. Table 1 shows the frequency counts and percents for instructional and ability groups (intermediate-low and intermediate-mid learners). Data from Table 1 shows that the intermediate-low learners from the online-hybrid group used more cognitive strategies (17\%) than their counterparts (8\% and 7\%), but intermediate-mid learners from the F2F-blended and control groups used more cognitive strategies $(15 \%$ and $16 \%)$ than the online-hybrid group (11\%).

The descriptive statistics associated with strategy use across the instructional and ability groups are reported in Table 2. In order to see if there was a statistical significance in means among instructional groups, a between-groups ANOVA was performed first for the intermediate-low learners. The assumptions of homogeneity of variances was violated based on Levene's F test, $\mathrm{F}(2,1448)=46.45, \mathrm{p}=.000$. Therefore, the Brown-Forsythe test was used due to unequal variances as well as unequal sample sizes. This test revealed a statistical significance difference in strategy use $\mathrm{F}(2,1141)=11.544, \mathrm{p}=.000$ among means $(1.16,109$, and 1.06) of the three groups for intermediate-low learners. To study which group was different from another the Games-Howell post hoc test was used because equal variance was not assumed. There was a significant difference between online-hybrid and F2F-blended (mean difference .072 , standard error .021, p = .003) and between onlinehybrid and control groups (mean difference .100 , standard error $.022, \mathrm{p}=.000$ ), but there was not a significant difference between F2F-blended and control groups (mean difference .028 , standard error $.017, \mathrm{p}=.230$ ) of intermediate-low learners. To study the differences in means $(1.10,1.15$ and 1.15) for the intermediate-mid learners, a between-groups ANOVA was performed. The assumptions of homogeneity of variances was violated based on Levene's F test, $\mathrm{F}(2,831)=6.250, \mathrm{p}=.002$. Therefore, the Brown-Forsythe test was used 
due to unequal variances as well as unequal sample sizes. There was not a statistical significant difference in strategy use $\mathrm{F}(2,830)=1.495, \mathrm{p}=.225$ among means $(1.10,1.15$, and 1.15) of the three groups.

Table 2. Descriptive statistics for overall strategy use for groups and proficiency levels

\begin{tabular}{ccccccccc}
\hline \multirow{2}{*}{ Groups } & \multicolumn{2}{c}{ Frequency } & \multicolumn{2}{c}{ Percent } & \multicolumn{2}{c}{ Mean } & \multicolumn{2}{c}{ SD } \\
& IL & IM & IL & IM & IL & IM & IL & IM \\
\hline Online-hybrid & 413 & 246 & 28.5 & 85.9 & 1.16 & 1.10 & .375 & .313 \\
F2F-blended & 630 & 297 & 43.4 & 35.6 & 1.09 & 1.15 & .295 & .359 \\
Control & 408 & 291 & 28.1 & 34.9 & 1.06 & 1.15 & .253 & .365 \\
\hline
\end{tabular}

Intermediate-low (IL) and Intermediate-Mid (IM)

R.Q.2: Does student listening comprehension strategy use develop over time without explicit instruction? Data from Table 1 revealed a metacognitive strategy use development for participants in the online-hybrid courses (83\% for intermediate-low learners and $89 \%$ for intermediate-mid learners), but not development for the use of cognitive strategies (17\% for intermediate-low learners and $11 \%$ for intermediate-mid learners). Data from the F2Fblended and control groups revealed a cognitive strategy use development $(8 \%$ and $7 \%$ for intermediate-low and $15 \%$ and $16 \%$ for intermediate-mid), but not development for metacognitive strategies (90\% and $93 \%$ for intermediate-low versus $85 \%$ and $84 \%$ for intermediate-mid learners). Results from Table 2 and ANOVA also indicated a development over time for cognitive strategy use with the face2face-blended and control groups. The means in Table 2 indicate that all instructional and ability groups seem to use more often metacognitive than cognitive strategies.

R.Q.3: Does providing redundant information in listening texts facilitate student use of certain strategies? 
Table 3. Frequency for strategy types among instructional and ability groups

\begin{tabular}{lcccc}
\hline \multicolumn{1}{c}{ Strategy types } & $\begin{array}{c}\text { Frequency } \\
\text { Control (IL) }\end{array}$ & $\begin{array}{r}\text { Frequency } \\
\text { OH (IL) }\end{array}$ & $\begin{array}{r}\text { Frequency } \\
\text { F2F-B (IM) }\end{array}$ & $\begin{array}{r}\text { Frequency } \\
\text { OH (IM) }\end{array}$ \\
\hline 2.Global prediction & 3 & 11 & 3 & 8 \\
4.Substitution & 22 & 4 & 3 & 4 \\
7.Directed attention & 101 & 55 & 68 & 45 \\
8.Selective attention & 54 & 35 & 32 & 41 \\
9.Double check monitoring & 28 & 39 & 39 & 24 \\
11.Performance evaluation & 8 & 42 & 17 & 10 \\
12.Problem identification & 30 & 15 & 6 & 2 \\
13.Comprehension monitoring & 5 & 1 & 1 & 0 \\
14.Translation & 1 & 3 & 5 & 4 \\
16.Note-taking & 2 & 0 & 1 & 0 \\
17.Summarization & 4 & 21 & 13 & 4 \\
18.Linguistic inferencing & 10 & 12 & 2 & 15 \\
19.Extralinguistic inferencing & 2 & 20 & 14 & 0 \\
23.Personal elaboration & 3 & 4 & 4 & 5 \\
25.Visual elaboration & 3 & 4 & 5 & 15 \\
\hline
\end{tabular}

Frequency counts for groups and levels of some strategy types

For intermediate-low participants one-way ANOVA was performed for strategy types among instructional groups. The assumption of homogeneity of variances was tested and rejected based on Levene's $F$ test $F(2,1448)=9.07, p=.001$. The Brown-Forsythe test was used for unequal variances and unequal sample sizes. This test revealed a significant difference in strategy types $\mathrm{F}(2,1285)=5.563, \mathrm{p}=.004$ among means (hybrid= 8.15, F2Fblended $=7.31$ and control=6.89) of the three instructional groups.

To study which group was different from another, the Games-Howell post hoc test was used because equal variance was not assumed. There was a significant difference between online-hybrid and control (mean difference 1.25, standard error.38, $\mathrm{p}=.003$ ), but there was not a significant difference between $\mathrm{f} 2 \mathrm{f}$-blended and online-hybrid groups. When looking at the frequency counts for both groups with a statistically signicant difference the learners in the online-hybrid group use more cognitive strategies than learners in the control group. 
However, the control group uses metacognitive strategies more frequently than its counterpart, such as direted and selective attention and problem identification.

For intermediate-mid participants one-way ANOVA was performed for strategy types among groups. The assumption of homogeneity of variances was tested and satisfied based on Levene's $\mathrm{F}$ test $\mathrm{F}(2,831)=.152, \mathrm{p}=.859)$. The independent between-groups ANOVA yielded a statistically significant effect, $\mathrm{F}(2,831)=3.27, \mathrm{p}=.038, \eta^{2}=.008$. Thus, the null hypothesis of no differences between means was rejected, and $0.08 \%$ of the variance in strategy types was accounted for by groups (F2F-blended, control and online-hybrid). To evaluate the differences between the three means further, the statistically significant ANOVA was followed-up with three Tukey's HSD post-hoc tests. The difference between online-hybrid and F2F-blended groups was statistically significant $\mathrm{p}=.048$, but there was not significant difference for the other groups. When looking at the frequency for both groups with a statistically signicant difference, it is clear that both groups use all strategy types, but the F2F-blended group uses twice as many metacognitive and cognitive strategies as the online-hybrid group.

\section{Conclusions}

Results from this study indicated that intermediate-low learners in an online-hybrid environment were perceived using more cognitive strategies than its counterparts. This was not unexpected because these learners are more accustomed to listening online without facial expressions, body language, kinesic information and perhaps are paying more attention to the tone of voice; therefore one could say that they have advantages over face2face-blended students for using cognitive strategies. Even if participants in this study were not explicitly taught listening strategies, data shows that learners use them. Moreover, they use more metacognitive than cognitive skills which is the key for L2 listening success (Vandergrift and Baker, 2015). The device of redundancy did not help participants using different strategies than their counterparts, but the frequency counts for cognitive strategies was evident for intermediate-low learners in the online-hybrid group. Perhaps the combination of instructional format and listening tests enhanced with redundancy helped to the use of more cognitive strategies.

\section{References}

Chen, L., Zhang, R., and Liu, C. (2014). Listening strategy use and influential factors in Web-based computer assisted language learning. Journal of Computer Assisted Learning, 30,207-219.

Goh, C. M. (1998). How ESL learners with different listening abilities use comprehension strategies and tactics. Language Teaching Research, 2 (2), 124-147. 
O’Malley, J.M. and Chamot, A.U. (1990). Learning strategies in Second Language Acquisition. Cambridge: Cambridge University Press.

Nogueroles López, M. and Blanco Canales, A. (2017). Un modelo de instrucción en estrategias: efectos sobre la competencia en comprensión auditiva. Journal of Spanish Language Teaching, 4:1, 75-89, doi: 10.1080/23247797.2017.1315268.

Pardo-Ballester, C. (2016). Using video in web-based listening tests. Journal of New Approaches in Education Research (NAER), Vol.5 (2), 91-98.

Roussel, S. (2011). A computer assisted method to track listening strategies in second language learning. ReCALL, 23 (2): 98-116.

Suvorov, R. (2018). Investigating test-taking strategies during the completion of computer delivered items from Michigan English Test (MET): Evidence from eye tracking and cued retrospective reporting. Cambridge Michigan Language Assessment (CaMLA) Working Papers 2018-02.

Vandergrift, L. (1999). Facilitating second language listening comprehension: acquiring successful strategies. ELT Journal, 53 (3), 168-176.

(2008). Learning strategies for listening comprehension. In S. Hurd \& T. Lewis (Eds.) Language learning strategies in independent settings. Bristol, UK: Multilingual Matters.

Vandergrift, L. and Baker, S. (2015). Learners variables in second language listening comprehension: An exploratory path analysis. Language Learning, 65 (2): 390-416. 